\title{
Trapped into Reverse Asymmetry: Public Employment Services Dealing with Employers
}

\author{
DARIO RASPANTI* (1) AND TATIANA SARUIS** \\ * Dario Raspanti, University of Florence \\ email: dario.raspanti@unifi.it \\ ** Tatiana Saruis, University of Modena and Reggio Emilia \\ email: tatiana.saruis@unimore.it
}

\begin{abstract}
Although often neglected, the availability of employment opportunities is central to the effectiveness of active labour market policies. Employers play a crucial role in this policy field as they are both clients and co-producers of public employment services (PES). This study focuses on that relationship and reports qualitative research conducted in Tuscany (central Italy) from a streetlevel perspective. The findings show how public job-brokers manage this asymmetrical relationship and develop specific strategies to obtain employers' cooperation and accomplish the PES mandate. The strategies identified here involve language adaptation, curricula "creaming", and control of the bureaucratic procedure. These are shaped through a variable mix of four components that will be defined as relational, perceptive, technical, and tactical. This study contributes to the debate on activation policies, analysing in detail how PES frontline workers interact with employers, dealing with market logic in the public encounter.
\end{abstract}

Keywords: Employer Engagement; Job intermediation; Discretion; Street-Level Bureaucracy; Public Employment Service

\section{Introduction ${ }^{1}$}

Employers play a dual role in relation to public employment services (PES) since they are both clients and potential co-producers of activation policies (van der Aa and van Berkel, 2014). As clients, they are voluntary as job-matching can be provided by other recruitment channels (Larsen and Vesan, 2012). As co-producers, their decisions create occupational opportunities for the people enrolled in activation programmes: both directly, if they are involved in the design and implementation of such programmes; and indirectly, if they trust PES as a labour intermediary (Bonet et al., 2013). As a result, employers do not conform to the traditional definition of a street-level bureaucracy's (SLB's) client, which is usually the weakest part of the relationship. In contexts where the employment services are public, and frontline job-brokers can be considered SLBs (Lipsky, 1980), their relationship with employers constitutes an interesting focus for observing the interaction between 
public and market logics. This means that frontline workers create specific approaches for interacting with them and accomplishing the PES mandate.

The SLB literature questions the role of frontline workers in their relationship and interaction with public services clients. Lipsky (1980) and later researchers (see, for example, Dubois, 2010; Mik-Meyer and Silverman, 2019) have indicated SLBs' discretion increases if the clients are involuntary and have reduced capacity or possibility of negotiation. The interaction between SLBs and employers has overturned this traditional asymmetry, as the latter are voluntary and are "powerful" clients. Since the employer's availability for hiring is crucial to accomplishing the mandate of PES frontline workers, the relationship with these clients implies essential challenges for frontline workers and the activation of specific strategies to provide employment opportunities for their unemployed clients.

This paper focuses on the job-brokerage service with which PES oversee an employer's recruitment process, from defining job requirements to the screening of job candidates, to increasing the probability of effective recruitment (Bonet et al., 2013). This study questions how the frontline workers interpret their role in this relationship and shape strategies to get the employer's cooperation, considering the opportunities and limits provided by the context in which they are embedded.

In order to investigate this topic, a case study was conducted in Tuscany, a region in central Italy. This study used a qualitative research method, based mainly on semi-structured interviews ${ }^{2}$ conducted in the PES located in the cities of Florence and Prato.

The study of the relationships between the PES and employers in Italy has been under-investigated (Raspanti, 2019). Furthermore, the street-level perspective is quite innovative in this country (Barberis et al., 2019). This case study will contribute to the debate on the "emerging activation regimes" (Coletto and Guglielmi, 2018) and the development of a street-level perspective in the south of Europe. The results of this analysis can be useful in the examination and comparison of other Countries and research contexts.

This study was driven by the following research questions. What are the challenges facing PES job-brokers, as SLBs, when working with employers? What kind of relationship do they establish and what are the conditions that influence their interaction with employers? How do the frontline workers use their discretion to facilitate an employer's co-operation? What strategies do SLBs develop to accomplish their service mandate and how are these shaped?

This study focuses on how job-brokers use discretion in taking decisions, contributing to shaping a service's practices and consequently labour policies and their outcomes. Similar to previous researches (van der Aa and van Berkel, 2014; Ingold, 2018), it highlights that job-brokers deal with employers developing specific strategies to get their cooperation and accomplish the PES mandate. The strategies identified follow. (1) Language switching - the frontline workers alternate professional and colloquial speech to gain an employer's trust. 
(2) Output maximisation - they re-adapt the submission process of the candidates' curricula (CVs) to increase job matching probabilities and to build long-lasting partnerships. (3) Red tape reduction - they speed up the procedures, negotiating a timing acceptable to an employer. This article argues that these strategies are shaped by a variable mix of components, which are defined as relational, perceptive, technical, and tactical.

The article is structured as follows. The next section provides the theoretical background to the analysis of the relationship between an SLB and its clients, focusing on previous studies of employer engagement. The third section explains the research context in which the case study was completed. After a brief methodological paragraph, the fifth section reports the empirical analysis and findings, identifying the strategies and components that characterise the discretion of frontline workers. The conclusions sum up the study's empirical and theoretical contribution to the literature, endeavouring to answer the research questions.

\section{The theoretical background}

\subsection{The relationship between SLBs and their clients}

Scholars have highlighted the vertical asset in the relationship between SLBs and their clients (Bartels, 2013). From Lipsky (1980) onwards, this relationship has been considered as usually based on information asymmetry, but also asymmetry in terms of power, resources, knowledge, and capabilities. A client's interaction with the street-level agencies is often involuntary, with little possibility of negotiation, voice, or exit (Dubois, 2010). These agencies provide essential services that cannot be attained elsewhere, due to the public services' monopolistic asset or a client's difficulty in affording private services (Lipsky, 1980). Within this relationship, the parties tend to a reciprocal adaptation through a process of socialisation to the bureaucratic context. According to the conditions of their interaction, they make decisions and create strategies aimed at their respective goals. This process is usually controlled and guided by the SLBs, especially if it involves poor and/or disadvantaged people (Lipsky, 1980; Dubois, 2010).

On the one hand, clients pass through a process of acceptance and adaptation to the bureaucratic redefinition of their identity in order to fit into the formal categories and criteria establishing access to benefits, but also to become a part of a relationship that they do not control. (Dubois, 2010). This learning process is not painless, as they are asked to accept their bureaucratic identity, remaining in an involuntary relationship and a subordinate position, with limited or no voice, and a possibility of exit. If they have been the services' clients for long periods, this disempowering and dependency-based relationship may create the basis for welfare "traps" (Ferrera, 1998). However, even the most vulnerable clients have a space of agency in their interaction with the services (Mik-Meyer and Silverman, 2019). In 
time, they may acquire familiarity with the services' (said and unsaid) rules, terminology, fulfilments, and procedures and discern the best stance to be taken and the most successful strategies for achieving what they seek. They may even learn how to cheat the system.

On the other hand, SLBs are socialised to a services' organisation and functions, developing decision-making strategies that take into account the conditions in which they work. They use their discretionary spaces to cope with the multiple pressures and even adverse situations and circumstances (e.g. limited resources, timing, heavy workloads). Their relationships with clients are standardised and routinised through the services' procedures in order to contain complexity and limit the stress of decision-making. They tend to adjust their language, behaviours, and decisions to their perception of client requests, behaviours, and even their status, gender, and ethnicity (Watkins-Hayes, 2009). One of their main concerns is to earn a client's cooperation to collect information and make appropriate decisions regarding the cases they deal with in order to do their job (Lipsky, 1980). Dubois (2010) describes how SLBs reshape their language and behaviours when meeting "powerful" clients, who appear to deeply understand the public system, know their own rights, and have the capacity and possibility to complain and manage a relationship with upper bureaucracies. They may be non-voluntary clients as they access monopolistic services, but they have a voice and expertise in dealing with the system and its rules. In this case, the relationship between SLBs and their clients is re-balanced and more horizontal, overcoming paternalistic or punitive assets. The services' bureaucratic procedures and waiting times are reduced; the assignment of benefits may even be readapted to these clients' requests.

A similar dynamic emerges in this paper's analysis of the relationship between PES frontline workers, who are public job-brokers, and employers, due to a reverse dependency. Employers are powerful, voluntary clients, and the SLBs have to adapt their strategies to gain cooperation. The subject of discretion is still crucial for understanding how they deal with these clients, taking into account the pressures of the situation in which they act. Discretion is usually analysed through a three-types classification: 1) discretion within the laws, including decision-making tasks assigned to professionals by laws and procedures, 2) discretion among the laws, such as decisions based on interpretations depending on contradictory, scarce or lacking laws and procedures, and 3 ) discretion out of the laws, such as violations of laws and procedures (Evans and Harris, 2004).

In short, the street-level perspective applied to this study allows the adoption of a bottom-up focus on the micro-relationships between public and private market actors. In particular, the concept of discretion (Evans and Harris, 2004) helps to highlight the former's strategies for dealing with a client's peculiarities, and how these are shaped, with the awareness that they will influence the implementation of a policy's macro-processes and outcomes. 


\subsection{PES frontline workers and employers: a relationship to be investigated}

Ingold and Stuart (2015) highlight that studies on activation policies have usually neglected the relevance of an employer's engagement ${ }^{3}$. The literature tends to be focused mainly on the dynamics of supply-side policies that involve job seekers and service providers, while the demand-side policies are discussed and analysed more rarely (Gore, 2005; van Berkel and van der Aa, 2012; Ingold and Valizade, 2017; Ingold, 2018). Nonetheless, studies conducted mainly in the UK (Gore, 2005; Hasluck, 2011; Ingold and Stuart, 2015; Ingold, 2018), Denmark (Bredgaard and Halkjær, 2016; Bredgaard, 2018), Norway (Mandal and Osborg Ose, 2015) and The Netherlands (van der Aa and van Berkel, 2014; van Gestel et al., 2019) have analysed the employer's involvement in policy programs. Apart from a comparative study on the demand side, carried out by Raspanti (2019) on southern European countries, contributions on this geographical area are lacking.

The literature describes the PES as not being commonly perceived as trustworthy by employers. According to Larsen and Vesan (2012), four drawbacks relate to public service involvement in labour-market intermediation, triggering a vicious circle that alienates employers from relying on the PES. Firstly, the PES' mandate requires that all the job seekers be supported regardless of their attractiveness in the labour market. Secondly, the PES support those unemployment-benefits recipients who are considered less valuable by employers as they may have lost their jobs because of being less productive. They also support the long-term unemployed whose skills may have possibly declined (Bonoli and Leichti, 2014). Thirdly, even those job seekers with valuable skills tend to consider the PES negatively and prefer to seek employment by using other strategies. Fourthly, employers (and valuable job seekers) often rely on peer or employee networks to have trustworthy information on a job seeker's qualifications. Although this channel is quicker and cheaper than the others, it may provide effective matches. The workers hired through these networks may not be the most suitable in terms of skills, yet they may have more effective social capital (Barbieri et al., 2000).

Many studies on the PES' relationships with employers concern their role in the activation of disadvantaged groups (e.g. the long-term unemployed, lowskilled workers, disabled people, and so on). Studying the possibility of successful activation programmes in the UK and Denmark, Ingold and Valizade (2017) argue that an employer's bias in recruitment decisions can be only slightly modified by the efforts of a PES because of their involvement.

A recent contribution by Orton and colleagues (2019) focused on a UK activation programme for young people. It highlighted that employers are less cooperative when they are asked to provide opportunities to job seekers; while they become more engaged when they are also involved in the design and implementation of the activation programmes. A similar distinction in the role of employers as "partners" and "clients" has been identified by van der Aa and van Berkel (2014), who 
underlined that, in both cases, the employer's collaboration is crucial for the success of labour activation policies. They also analysed the employers' views of their participation in these policy programmes, highlighting a combination of motivations including the search of new workers, a cut in placement costs, and compliance with corporate social responsibilities.

However, the study proposed here concentrates on the other side of the relationship between PES frontline workers and employers: the perceptions and strategies of public job-brokers' when dealing with these clients have their cooperation in meeting the PES' aims. This issue is becoming progressively crucial for activation literature, with interesting contributions both from the perspectives of SLB (Ingold, 2018) and of human resources management (Bonet et al., 2013; van Berkel et al., 2017).

A study by Ingold (2018) reports three strategies deployed by PES staff to achieve an employer's cooperation. The first is based on $\mathrm{B}_{2} \mathrm{~B}$ sales approach in which job seekers are promoted as "products" to employers, while the employers are considered "clients". A second strategy seeks to influence an employer's recruitment processes, interpreting their needs and screening job candidates accordingly. These approaches could be respectively identified as demand-led and demand-oriented (van der Aa and van Berkel, 2014; Ingold, 2018). A third strategy aims to achieve a long-lasting relationship with employers, building a stable and personal bond through informal and emphatic interactions. Inspired by these findings, the present article will study in depth the job-broker's strategies for dealing with employers.

\section{The research context}

Italy is considered an "emerging activation regime". The recent efforts to modernise the system have collided with a low investment of resources in these policies, limited support for unemployed and biased towards monetary provisions, and local fragmentation in service delivery (Coletto and Guglielmi, 2018).

Labour market policy is delivered through a multi-level governance system. The National Agency for Active Labour Market Policies sets the main targets of labour-market policy; it also coordinates and support the regions, which are responsible for activation strategies in their territory, the organisation and management of the local public job-centres (called Centri per l'Impiego - CPIs), and service delivery to job seekers and employers. Although a national reform in 2015 centralised the institutional powers regarding labour activation ${ }^{4}$, the capability to control and steer the regional employment services is still lacking at the national level, due mainly to two reasons: the ineffective management arrangements that do not permit the implementation of the national tools for measuring and assessing regional performances and a significant autonomy assigned to the 
regions that prevents any sanctions in case of non-compliance with national programmes and aims (OECD, 2019).

Even though in recent years employers have become a specific target group for CPIs, their relationship with the public service is not regulated by national law and the commitment to their needs at the regional level is still insufficient (OECD, 2019). Employers are obliged only to communicate job hiring but not to register job vacancies on public job-boards. Employer subsidies to hire candidates from PES are absent ${ }^{5}$.In fact, PES compete with private providers for labour intermediation, and very few companies address them as matchmakers. According to Mandrone and colleagues (2016), in Italy, the public service is used on average by only $1.5 \%$ of enterprises. This data increases to $2.4 \%$ among small enterprises (10-49 employees), while it is the lowest among the large enterprises (o.4\%). Employers usually prefer to rely on informal contacts based on personal trust (especially small companies), private providers, employers' organisations, and their own databases.

Florence is an important business centre due to the presence of large multinational corporations; it has a significant tourist sector and a well-developed system of small and medium enterprises in its neighbourhoods. The economic area around Prato is prototypical of the Italian SME-led-economy. Its industrial district is specialised in the export-led woollen and clothing sectors (Guercini et al., 2017). According to the National Institute of Statistics, the unemployment rate in 2018 was $5.8 \%$ in Florence, and $6.7 \%$ in Prato, in line with north and central Italy.

When the fieldwork took place, in the Tuscan Region, the PES were directly dependent on the regional government through the Labour Directorate ${ }^{6}$. The region established a public-oriented model of service provision, in which the 41 CPIs are responsible for the delivery of the most important services, assigning a complementary role to private providers. Marketing and counselling services were contracted-out to a consortium composed of vocational training and employment services providers, due to a lack of personnel.

According to the regional chart of service (Regione Toscana, 2017), the job-brokerage service falls within the employer-oriented services managed by the CPIs. The job-brokers are all civil servants and perform the following tasks. Firstly, they identify the components of the employer's demand in terms of skills and expertise required to fill the vacancy. Then they publish the job offer on the public service's online job-board, which is their main work tool. Thirdly, they compile a shortlist of CVs of those job seekers who meet the employer's criteria. The CVs come from a database of unemployed people registered with the PES, from caseworker reports on the participants to tutoring and training activities, and from job seeker applications to the job-board. Eventually, job-brokers send a shortlist to the employer, checking to see if they have contacted the shortlisted job seekers. 
The PES accountability system is weak. The regional Labour Directorate collects performance data from local job-centres to support regional policy-making and organisational arrangements, but do not have any impact in terms of rewards or sanctions. In the realm of labour intermediation, there are neither national nor regional performance management requirements that may influence an SLBs' behaviour at the frontline. The empirical study presented here has revealed that a few local managers have established annual quantitative goals to control the effectiveness of frontline practises in terms of the number of employers involved, vacancies processed and matches achieved. Even these sets of goals do not correspond to a system of sanctions in any of the cases. The results are shared and analysed by the CPIs' staff to analyse their own strategies and practices.

The study shows that job-centre managers assign job tasks to frontline workers on a daily basis to deal with personnel shortages ${ }^{7}$. Job-brokers are frequently deployed to unemployed services to cover excessive caseloads, rather than to manage job offers. Only in the two largest cities are job-brokers dedicated to employer services on a permanent basis. In the city of Florence, the Employer Engagement Unit employs three frontline workers to cover the entire city area. In Prato, the Employer Engagement staff is composed of two job-brokers. However, one of them interacts daily with unemployed individuals. It is worth noting that some of the managers interviewed evaluated their staff's involvement in multiple tasks positively, as it is supposed to increase their awareness of both the employer's and the job seeker's requirements.

\section{Methods}

This paper's findings are based on 38 semi-structured interviews conducted in 10 public job-centres located in the provinces of Florence and Prato, in the Tuscany Region - Italy. Moreover, three functionaries from the Labour Directorate of the Region and two from the provincial level were interviewed to contextualise the PES roles within the regional labour market policy strategy. Contacts with interviewees were established with top-down snowball sampling ${ }^{8}$. Interviews took place in the services during closing time for the service. The majority were individual interviews. However, some were conducted collectively 9 .

The average age of the sample is 48 and most of the job-brokers are women. It is possible to identify three professional profiles. The first is composed of people with varying levels of education and long careers in public administration, although not necessarily in the employment sector. The second group consists of people trained as social workers, who have always worked in employment public services. A third group includes people with extensive training and careers in labour intermediation and previous experience in private agencies.

The interviews covered (a) the interviewees' career paths; (b) the daily organisation of their tasks; (c) their relationships with their manager, colleagues and 
employers; and (d) their interpretation of the role as labour market intermediaries and public servants.

All the interviews were recorded and transcribed with the consent of the interviewees who were informed that their comments would remain confidential. Observational notes were collected during and after the interviews. All the materials were analysed with the support of the qualitative data analysis software NVivo 12. Key issues concerning frontline workers' discretion were identified initially in the transcription files. Secondly, they were coded and grouped into categories reported by the literature. Thirdly, the strategies and their components were identified in the qualitative data through an inductive procedure.

\section{Reverse asymmetry explained}

\subsection{Characteristics of administrative relations with employers}

As explained in the theoretical framework, one of the main concerns of street-level bureaucrats is to gain their clients' cooperation (Lipsky, 1980), as they need this to "do their job" (collecting information, making decisions, and so on). A client's dependency on services and benefits may turn into deference toward the public service, easing street-level bureaucrats into performing tasks and delivering services (Dubois, 2010). Regarding employers, the literature on employer engagement highlights the autonomy of employers as clients and their role regarding the achievement of activation policy outcomes (van der Aa and van Berkel, 2014; Orton et al., 2019), reversing the dependency relationship to the detriment of the job-broker in driving the service relationship.

Moreover, the PES' position is weakened by the fact that employers may rely on other channels for recruiting workers. Informal networks and private providers are often preferred to public services due to the fact that they are perceived as more effective (Larsen and Vesan, 2012). Even though the service is a cost savings for employers as it is provided free of charge by the public job-centres, the provision of a free service turns out to be a double-edged sword as interviewees have reported that it leads to an employer's indifference regarding the intermediation outputs. To gain an employer's commitment, job-brokers are pushed towards improving the effectiveness of the intermediation service, as stated in the following quote.

"Enterprises, reasonably, use all channels [of intermediation]. We are one of many channels. We live in a competitive world, and so... you know, either we sell [the service] or the product properly, or we sell a better product, right? Anything more that is not just a free service" [Frontline worker]

The relevance and difficulties of obtaining an employer's involvement are usually disregarded in activation policy programmes and almost entirely left as a sort of secondary task to street-level organisations (OECD, 2019). However, the 
public service need information on employer vacancies to foster the job outcome of supply-side measures. Thus, a job-broker's aim is to increase their clientele and to establish lasting relationships. Differently from traditional street-level bureaucrats, who are focused on reducing their caseloads (Lipsky, 1980), job-brokers do not consider employers as a cost but rather a resource. Their relationship with employers is reversed in the sense that dependence and deference affect the frontline worker more than the employer, reversing the traditional frontline worker-client distribution of resources, information, and agency. The next quote shows how the need for collaboration changes a manager's and a job-broker's disposition regarding their tasks and duties, while affecting their perception towards service provision at the same time.

"With employers you need ... you know, a sort of ... I wouldn't say empathy, but rather the ability to put ourselves in the employer's shoes. Because the employer has asked us for a service. When a company asks to use our service, we then respond to the company. In other words, by streamlining our administrative practices and responsiveness to citizens. We have this sort of long-standing approach. So, you know ... we must be focused on the goal because we are face-to-face with the enterprise as client. He makes a request. Thus, 'how are we going to get closer to comply with enterprise's requests?"”

[Manager]

This asymmetrical relationship affects the bureaucratic encounter and produces some interesting effects on job-broker's strategies in dealing with employers, as explained in the next paragraph.

\subsection{Frontline workers and reverse asymmetry}

Job-brokers can shape three strategies to manage the reverse asymmetry in their relationship with employers and gain cooperation: language switching, output maximisation, and red tape reduction. These strategies are inspired by Ingold (2018), readapted on the bases of our research's findings, and explained above.

\subsubsection{Language switching}

A first strategy is language switching. Frontline workers try to overcome the differences among employers' and administrative professional languages: they use a lexicon that should be more familiar and understandable for the clients to achieve a collaborative arrangement as well as get information and gain trust. In the following quotation, a job-broker explains that he collects information about an employer's request in terms of skills, "translating" the job classifications he uses to record the job offer in the regional database. This classification, that is used to compose the job ad, is not easily understandable by the clients:

"[On the online job-board,] I've got the ISFOL classification ${ }^{10}$, you know. Enterprises don't speak ISFOL's language. If you get lucky, and the enterprise is somewhat structured, the 
employer speaks the vocabulary of collective agreements ${ }^{11}$. Bars, restaurants, pizzerias don't even speak the language of collective agreements"

[Frontline worker]

If necessary, frontline workers switch from an informal to a technical lexicon to demonstrate their own expertise in order to overcome eventual bias by employers regarding the PES' efficiency and professional skills. Their knowledge about the market sectors in which the employers operate should make not only employers perceive SLBs as professionally competent, but also establish an empathic connection. For this reason, they also share considerations about economic difficulties due to market fluctuations, thus, showing empathy with employers' complaints about their condition and necessities. Even though this strategy is learned through experience, a frontline worker's education plays a role. As one job-broker explains:

"Dealing with enterprises, as I do, is different from dealing with people. In fact, I handle the technical aspects because I am an industrial technician. and I know everything about the wool industry. When we have to involve employers, I even understand what they are looking for."

[Frontline worker]

This strategy shows a use of discretion within the law, as the frontline workers use their professional as well as their personal and experiential knowledge in order to better achieve the PES' aims. It includes and mixes a relational component based on an empathic approach (like showing understanding of business needs and problems) and a perceptive component that indicates professional knowledge and skills to improve an employer's perception of the service.

\subsubsection{Output maximisation}

A second strategy is aimed at output maximisation. Job-brokers control the number of the selected candidates included in the list of CVs to be sent to an employer. Indeed, sending unfiltered lists of candidates containing numerous applications may result in an employer's disengagement (Larsen and Vesan, 2012; Ingold, 2018). As frontline workers are obliged by law to send employers all suitable CVs, they may apply stricter selection criteria if the number of applications is high. This decision uses discretion within the law, as selecting CVs according to a candidate's qualifications is a task that falls within a frontline caseworker's mandate.

However, the selection could still not be strict enough in relation to an employer's request. It must be noted that, according to the law, all the suitable CVs should be presented to employers. In order to both avoid overwhelming them with too many candidates and respect the law (which requires that all CVs be passed on to the employer), frontline workers may decide to send the CVs in different tranches established on the basis of a "creaming" process. 
The applications with the best chances of success are sent in advance to make it easier for the employer to screen them; then all the others are sent. This is a use of discretion among the laws: this decision does not violate the law (as all the suitable candidates are finally proposed to the employer), but the frontline worker mediates between the law's mandate regarding equal opportunities being offered to all job seekers and an employer's need for a strict pre-selection.

Frontline workers may further reduce the number of candidates through discrimination. Employers may ask to apply non-professional criteria in the CVs selection related to a job seeker's personal information, which are forbidden by law (e.g. age, sex, race, ethnic group, marital status, religion, and political affiliation $)^{12}$. The public nature of a job intermediation service requires impartiality and non-discrimination in the selection and treatment of clients. The over-filtration based on discrimination is a case of discretion outside the law: a violation of a job seeker's rights and equal opportunities. This strategy is intended to prevent employers from receiving unwanted CVs that they would not consider for hiring people. Through these kinds of decisions, SLBs seek, on the one hand, to avoid any conflict with employers, while, on the other hand, providing a selection of CVs that satisfy their (even inappropriate) requests, so as to ultimately increase the availability of job opportunities for all future job seekers.

As stated in the following quotation, contradictions arise when an employer's expectations collide with service rules. Job-brokers face a dilemma between maximising the service's outcomes and guaranteeing equal opportunities to all candidates.

"If you stop to think for a moment that one hundred people are applying, you send [the employer] twenty. The remaining eighty won't have that opportunity to meet the employer. And if I send them all at once? It's the same! They wouldn't have an opportunity to meet the employer. The company that receives one hundred curricula says, “They're crazy!" and doesn't open any of them. And the ones I don't send? The ones I don't send probably don't fit this vacancy, but maybe would have been suitable for another."

[Frontline worker]

Indeed, job-brokers may negotiate an employer's expectations and requests, pushing them to consider job seekers not entirely consistent with the job's requirements or ascribed characteristics. Interviewees explain that influencing an employer's decisions and reinforcing their sense of social responsibility is possible when they have already relied positively on the service in the past.

In this strategy, a mix of mainly technical and tactical components emerge. They are grounded, on the one hand, on streamlining the procedures and controlling the service's output; on the other hand, on taking decisions oriented to building long-lasting collaborations, even neglecting current job seekers' rights in favour of increasing the opportunities for future job seekers. This strategy also shows the attempt to control and improve employers' opinions on service's 
efficiency, thus the perceptive component. Finally, the relational component emerges in the conflict-avoidance and indulgence on employers' prejudices.

\subsubsection{Red tape reduction}

The third strategy is Red tape reduction. This strategy is aimed at containing the duration of bureaucratic procedures. This should reduce an employer's perception of time wasted in dealing with the service. One example concerns the management of calls for applications. According to the law, frontline workers can establish the time frame in which to accept the candidatures for job offers. The CVs cannot be sent to employers before the call period is closed and all of them collected, in order to not exclude any candidates. Most of the employers need suitable candidates as soon as possible, yet the longer the call stays open, the higher the probability of finding a suitable candidate. Together with the employer, the frontline worker decides the proper length of the call by looking at their requests. Field research has highlighted that this timing is negotiated with the employer, who creates pressure for receiving the CVs as rapidly as possible. The frontline workers can reduce the number of days the vacancy remains open for candidates to apply, using discretion within the law. They may also decide not to send the suitable candidates all together to employers, but do so in various tranches: they could send part of the CVs while the call is open (to reduce the waiting time for employers); then send all the others, in other tranches or all together. In this case, the frontline workers use their discretion among the laws: indeed, the decision does not exclude suitable candidates from the selection, yet it allows the employer to receive the CVs in before the call's time frame has expired.

In this strategy, the technical component prevails, based on curbing the procedures in order to contain their timing. However, this tailored improvement of the service on the bases of an employer's needs and timing also recalls the perceptive component, which shows a professional approach, and the tactical component, in terms of building long-lasting relationships, by also reinterpreting or breaking the rules that should guarantee candidates' equal opportunities.

As highlighted, the relationship between job-brokers and employers is characterised by a mix of asymmetric agency capacity, complex strategies, and variable components. In the final section, these findings are summed up and discussed.

\section{Discussion and conclusion}

The article has examined the relationship between public job-brokers and employers in one of Italy's regional PES from a street-level perspective. The relationship has been described as a reverse asymmetry, underlining the vertical asset and the dependency link between an employer's decisions and PES outcomes. In fact, employers play a dual role concerning PES: they are both clients and 
co-producers of policies, as they influence the availability of job opportunities for those job seekers who have access to the services.

For this reason, frontline workers tend to foster their relationships with employers and make additional efforts in comparison with the prescribed tasks to gain their cooperation. They offer employers tailored support, adapting service procedures and meeting their requests in terms of the job seeker's qualities.

However, their approach is more complex than it appears. Frontline workers have to deal with the contradictions arising between rights, needs, and interests of a job seeker and an employer and take into account the opportunities and boundaries defined by the organisations in which they work and the labour market's characteristics. As scholars have argued (van der Aa and van Berkel, 2014; Ingold, 2018), they develop specific strategies to interact with employers.

The strategies of PES frontline workers emerging in this study can be summed up as follows. (1) Through a language switching strategy, the job-brokers work to gain an employer's trust, showing professional capability and a familiarity with their life and work to establish an empathic connection. In this case, discretion is used within the law, as managing this relationship is part of a frontline worker's tasks, but with additional effort aimed at building (a possibly long-lasting) partnership. (2) The output maximisation strategy seeks to contain the number of the candidates selected for the job offers. As frontline workers, they are obliged by the law to send employers all suitable CVs and to apply a strict selection based on their professional skills and the number of applications received. Even this decision is taken within the law as a task foreseen in the frontline caseworker's mandate. They can also decide to send the CVs in different tranches defined on the basis of a "creaming" process. This is a case of discretion among the laws because frontline workers find a middle ground between the law's mandate regarding the opportunities to be offered to all job seekers and an employer's need for a severe pre-selection. Furthermore, as explained previously, frontline workers may further reduce the number of candidates through discrimination, if asked by an employer. This over-filtration anticipates the use of discretion outside the laws as a violation of a job seeker's rights, putting at a disadvantage the weakest, whose CVs tend to be "parked" by the service (Ingold, 2018). This strategy attempts to avoid conflicts with employers by sending them CVs that they would not consider for hiring. Thus, the individual right of a job seeker to equality and non-discrimination is neglected to satisfy an employer's inappropriate requests and to increase the availability of job opportunities for all future job seekers. Indeed, job seekers may try to improve an employer's recognition of social responsibility when they have built a positive relationship with them. (3) The red tape reduction strategy consists of controlling the duration of the bureaucratic procedures and an employer's perception of time wasted while dealing with the service. According to the law, frontline workers can establish the time available for accepting candidatures for job offers. Our field research has highlighted that this timing is negotiated with employers, which creates pressure to receive the CVs as 
rapidly as possible. This is a case of interpretation and thus of discretion among the laws. However, if the frontline workers decide to send the CVs before the call's deadline has expired, they violate the law.

A job-broker' strategies are established by using their various discretionary "spaces". It is worth noting that job-brokers do not inevitably bend the regulations to meet an employer's request, nor do they strictly follow the rules to reduce caseloads. Contrary to what Ingold (2018) observed, they may adopt a demand-oriented approach (van der Aa and van Berkel, 2014). This could be due to the public characterisation of the services analysed, which makes it necessary to combine a public and a market logic. The comparison between a public and a private job-broker's strategy could be a potential topic for future research in this or other contexts.

However, from the analysis of the reverse asymmetric relationships here presented, four interrelated components emerge that have been variably combined in their decisions. First is a relational component based on the utilisation of an empathic approach aimed at gaining an employer's trust, e.g. showing understanding for business necessities and difficulties. This is an active search for compliance and special attention to avoid conflict. For example, in the case analysed, an employer's prejudice may not be contrasted or ignored, but taken into account during the CV selection. Second is a perceptive component that shows an appropriate knowledge and professional competence for improving an employer's opinion and perception of the service. It could be based, for example, on a particular use of the language and vocabulary to showing professional expertise in the employer's sector. Third is a technical component grounded on streamlining the procedures, controlling the output (for example, manipulating the CV selection), limiting the time frame. The component does not concern only the effective meeting of an employer's request, yet it also affects the perception of the service by the employer (described in the previous component). Finally, there is a tactical component based on improving the service's effectiveness and/or efficiency. For example, frontline workers could assume a pragmatic approach to developing a long-lasting partnership with an employer. In the case study, it implied both rule-bending and breaking to comply with an employer's requirements even at the expense of a job seeker's right to equal treatment. In their intermediation mandate, job-brokers are embedded in a relationship between three participants, in which they are not always the most powerful, but in which the job seekers remain the weakest. However, this study did not see the effects of these strategies being applied to a job seeker's access to job opportunities, as this was not its focus.

The case study conducted in Italy contributes to the debate on activation policies and to the study of the "latecomers" in this policy area, typically the southern European countries (Coletto and Guglielmi, 2018). The analysis of job-broker strategies and their components contributes to the comprehension of the SLBs' use of discretion in their interactions with "stronger" clients. These results could 
be useful categories for analysing other contexts and even for proceeding with qualitative and quantitative comparisons in order to bring out both how widespread they are, and how specific or similar they are in other contexts.

This study could be also interesting for policy makers and practitioners of labour-market intermediation, especially in contexts similar to the one investigated here, in which a job-broker's role in getting an employer's engagement is neglected. In order to expand and reinforce the effectiveness of public services in labour intermediation, this task should be clearly defined in the PES' mandate, assigned to job-brokers with specific training, explicitly included in their workloads responsibilities, perhaps supported by incentives, and supervised with specific accountability mechanisms on their use of discretion.

\section{Notes}

1 This paper is the result of joint work and exchange between the authors. However, sections 1, 2, 6 are to be attributed to Tatiana Saruis, and sections 3, 4, 5 to Dario Raspanti.

2 The article is rooted in the data collected the $\mathrm{PhD}$ research done by one of the authors. The study received no financial support from any institution.

3 This term in the literature can refer to both an employer's involvement in the design and implementation of an activation programme and to their availability for hiring. This paper focuses on the second meaning.

4 Legislative decree no. 150/2015.

5 The national legislation on compulsory employment of differently-abled people (L. 68/ 1999) provides benefits for employers who hire from this pool.

6 Shortly after the conclusion of the interviews, Regional Law no. 28/2018 introduced the Regional Agency for the Employment (ARTI) as an independent body under the control of the regional government. ARTI is currently overseeing public job-centres in Tuscany.

7 Personnel shortage is one of the main concerns of Italian PES. According to the OECD (2019), the ratio in Tuscany of clients-per-frontline worker is remarkably high - with almost 400 unemployed individuals per PES employee - although lower than the national average. All the managers interviewed pointed to personnel shortages as the main weakness of the public service.

8 The Labour Director was asked to give permission to contact the job-centre managers, who indicated the frontline workers to be interviewed. Snowball sampling allows reaching as many job-brokers as possible, despite a possible selection bias related to non-random sampling.

9 The simultaneous presence during the interviews of both frontline workers and their managers can be considered a possible distorting factor. However, it was accepted as it allowed reaching many more interviewees and directly observing their interactions.

10 ISFOL is the former Institute for the Development of the Vocational Training of Workers, attached to the Ministry of Labour and social policies and currently denominated INAPPNational Institute for the Analysis of Public Policies. The interviewee refers to the Repertoire of Professions, which identifies 350 different items to codify employers' job requirements.

11 A collective agreement defines employment and working conditions - e.g. working time and task-related issues - and minimum wage levels in a given sector.

12 Legislative decree no. 276/2003. 


\section{References}

Barberis, E., Paraciani, R. and Saruis, T. (2019), 'Nota introduttiva al focus. Tra il dire e il fare: la prospettiva street-level e l'implementazione delle politiche di welfare', Politiche Sociali, 6, 3, 389-406.

Barbieri, P., Paugam, S. and Russell, H. (2000), 'Social Capital and Exits from Unemployment', in D. Gallie and S. Paugam (eds.), Welfare Regimes and the Experience of Unemployment in Europe, Oxford: Oxford University Press, 200-217.

Bartels, K.P.R. (2013), 'Public encounters: The history and future of face-to-face contact between public professionals and citizens', Public Administration, 91, 469-483.

Bonet, R., Cappelli, P. and Hamori, M. (2013), 'Labour Market Intermediaries and the New Paradigm for Human Resources', The Academy of Management Annals, 7, 1, 341-392.

Bonoli, G. and Leichti, F. (2014), Job market signalling, labour market disadvantage and activation, Paper presented at XII Annual ESPAnet Conference, 4-6 September 2019, Oslo.

Bredgaard, T. (2018), 'Employers and Active Labour Market Policies: Typologies and Evidence', Social Policy \& Society, 17, 3, 365-377.

Bredgaard, T. and Halkjær, J. L. (2016), 'Employers and the Implementation of Active Labor Market Policies', in Nordic Journal of Working Life Studies, 6, 1, 48-59.

Coletto, D. and Guglielmi, S. (2018), 'Activation policies in action: Unemployed people and public officers in face of the economic crisis', International Journal of Sociology and Social Policy, 38, 3/4, 329-344.

Dubois, V. (2010), The Bureaucrat and the Poor. Encounters in French Welfare Offices, Farnham: Ashgate.

Evans, T. and Harris, J. (2004), 'Street-level Bureaucracy, Social Work and the (Exaggerated) Death of Discretion' British Journal of Social Work, 34, 6, 871-895.

Ferrera, M. (1998), Le trappole del welfare, Bologna: Il Mulino.

Gore, T. (2005), 'Extending Employability or Solving Employers' Recruitment Problems? Demand-led Approaches as an Instrument of Labour Market Policy', Urban Studies, $42,2,341-353$.

Guercini, S., Dei Ottati, G., Baldassar, L. and Johanson, G. (2017), Native and Immigrant Entrepreneurship. Lesson from Local Liabilities in Globalization from the Prato Case Study, Cham: Springer International Publishing.

Hasluck, C. (2011), Employers and the Recruitment of Unemployed People: An Evidence Review, Briefing paper December 2011, London: UK Commission for Employment and Skills.

Ingold, J. (2018), 'Employer Engagement in Active Labour Market Programmes: The Role of Boundary Spanners', Public Administration, 96, 4, 1-14.

Ingold, J. and Stuart, M. (2015), 'The Demand-side of Active Labour Market Policies: A Regional Study of Employer Engagement in the Work Programme', in Journal of Social Policy, 44, 3, 443-462.

Ingold, J. and Valizade, D. (2017), 'Employers Recruitment of Disadvantaged Groups: Exploring the Effect of Active Labour Market Programme Agencies as Labour Market Intermediaries', Human Resource Management Journal, 27, 530-547.

Larsen, C.A. and Vesan, P. (2012), 'Why Public Employment Services Always Fail. Doublesided Asymmetric Information and the Placement of Low-skill Workers in Six European Countries', Public Administration, 90, 2, 466-479.

Lipsky, M. (1980), Street-level bureaucracy. Dilemmas of the individual in public services, New York: Russel Sage.

Mandal, R. and Osborg Ose, S. (2015), Social responsibility at company level and inclusion of disabled persons: the case of Norway, Scandinavian Journal of Disability Research, 17, 2, 167-187.

Mandrone, E., Landi, R., Marocco, M. and Radicchia, D. (2016), I canali di Intermediazione e $i$ Servizi per il Lavoro, Roma: ISFOL Research paper n. 31/2016.

Mik-Meyer, N. and Silverman, D. (2019), 'Agency and clientship in public encounters: co-constructing 'neediness' and 'worthiness' in shelter placement meetings', The British Journal of Sociology, 70, 5, 1640-1660. 
OECD (2019), Strengthening Active Labour Market Policies in Italy. Connecting People with Jobs, Paris: OECD Publishing.

Orton, M., Green, A., Atfield, G. and Barnes, S. (2019), 'Employer Participation in Active Labour Market Policy: from Reactive Gatekeepers to Proactive Strategic Partners', in Journal of Social Policy, 48, 3, 511-528.

Raspanti, D. (2019), Coping with a Voluntary Client. Frontline Workers in Public Employment Services Dealing with Employers' Recruitment Needs, Politiche Sociali, 6, 3, 427-446.

Regione Toscana (2017), 'Carta dei Servizi dei Centri per l'Impiego della Regione Toscana, Allegato A', Firenze: Regione Toscana.

van Berkel, R., Ingold, J., McGurk, P., Boselie, P. and Bredgaard, T. (2017), 'Editorial Introduction: An Introduction to Employer Engagement in the Field of HRM. Blending Social Policy and HRM Research in Promoting Vulnerable Groups' Labour Market Participation', Human Resource Management Journal, 27, 4, 503-513.

van Berkel, R. and van der Aa, P. (2012), 'Activation work: policy programme administration or professional service provision?', Journal of Social Policy, 41, 3, 493-510.

van der Aa, P. and van Berkel, R. (2014), 'Innovating job activation by involving employers', International Social Security Review, 67, 2, 11-27.

van Gestel, N., Oomens, S. and Buwalda, E. (2019), 'From quasi-markets to public-private networks: Employers' engagement in public employment services', Social Policy \& Administration, 53, 3, 434-448.

Watkins-Hayes, C. (2009), The New Welfare Bureaucrats. Entanglements of Race, Class, and Policy Reform, Chicago, University of Chicago Press. 